\title{
An extensive analysis of the health hazards for RMG workers in apparel sector of Bangladesh
}

\begin{abstract}
Since the 1980s, the Ready-Made Garment (RMG) industry in Bangladesh has encountered fast development and is at present positioned the second most elevated exporter on the planet after China. The RMG business has made a generous commitment to the economy and society by fundamentally giving a wellspring of work to around over 4,000,000 laborers, for the most part, ladies. This amazing development is subverted by the absence of safety in the factories and industrial accidents, which has defined the health hazards associated with the RMG division. These mishaps stunned the nation and the worldwide network. Because of these mishaps, the Government of Bangladesh and the advancement accomplices have prepared extraordinary help and made responsibilities to improve working conditions and worker's safety in the RMG business in Bangladesh. This paper is an endeavor to confirm the advancement and execution level of various activities taken by Bangladesh Government and the worldwide purchasers and retailers of RMG explicitly in the field of occupational health hazards, for example, health and hygiene, safety, other issues of health, hygiene and safety, welfare as well as OHS management system \& training. A useful study was done straightforwardly on RMG laborers to rough their insight level on consistency factors and their comprehension and acknowledgment of the current acts of occupational health hazards and safety in RMG manufacturing plants.
\end{abstract}

Keywords: RMG, occupational health and safety, RMG workers, health hazards
Volume 6 Issue 4 - 2020

Taosif Ahmed,' Rony Mia, ${ }^{1,2}$ Md Navid Tanjim, ${ }^{3}$ Md Azhar Waqar, ${ }^{4}$ Bulbul Ahmed, ${ }^{5}$ Md Mahamudul Hasan, ${ }^{6}$ Anik Das, ${ }^{4}$ Al Mojnun Shamim,' Khurshid Jahan,' Md Abdullah Al Fahad $^{7}$

'Department of Textile Engineering, National Institute of Textile Engineering \& Research (NITER), Bangladesh

${ }^{2}$ College of Chemistry \& Chemical Engineering, Wuhan Textile University, China

${ }^{3}$ Department of Public Health, North South University, Bangladesh

${ }^{4}$ Department of Applied Chemistry \& Chemical Engineering, Noakhali Science \& Technology University (NSTU), Bangladesh ${ }^{5}$ Department of Textile,Apparel \& Merchandising, Louisiana State University, USA

${ }^{6}$ Department of Textile Engineering, World University of Bangladesh, Bangladesh

${ }^{7}$ Department of Pharmacy, Khulna University, Khulna, Bangladesh
Correspondence: Rony Mia, Research Assistant, College of Chemistry \& Chemical Engineering, Wuhan Textile University, Wuhan 430073, China, Tel +86-15623233835,

Emailmroni_mia@niter.edu.bd

Received: July 06, 2020 | Published: July 27, 2020

\section{Introduction}

The off the shelf garments (RMG) sector has been a major contributor to Bangladesh's (BD) economy for several decades now. At present, in Bangladesh the RMG division has an export value of 34.13 billion USD per year approximately. This takes up around $82 \%$ of the country's entire export earnings. ${ }^{1}$ Currently Bangladesh is presumed to have around four to five thousand garment factories, ranging from substantial first-tier suppliers to small industrial units for the most part functioning as subcontractors to big clients. ${ }^{2,3}$

Occupational health points towards the recognition and limitation of the risks that are derived from physical, chemical and other workplace perils to construct and sustain a secure and healthy work environment. ${ }^{4}$ If work is associated with health hazards, it may stimulate occupational ailments. They may also exasperate existing non-occupational ill-health or medical condition. In developing countries, where many steps of manufacturing are mechanized, various working methods have been established which treat workers as tools in a production, risking their health and lives. ${ }^{5}$

Workplaces that are designed, according to high-quality principles of occupational health, safety, and ergonomics are the most sustainable and fruitful. And these components together bring successful economies. Also, In Poor working conditions where workers are exposed to a healthy and safe hazardous environment, one cannot expect a healthy economy, high quality of products or services, and long-term productivity from that working group.

\section{Research questions, objectives $\&$ scopes of the report}

The main research question of this study is "How much effectively and efficiently the garments factories are practicing their occupational health \& safety issues in terms of Bangladesh Labor Act, 2006"?

So, in terms of research questions the primary objective is:

a. To identify the health and safety compliance in terms of BLA, 2006

b. To locate out the causes of the health and safety hazards of garments workers

c. To assess the possibility of reduction of health and safety hazards

To fulfill the objective factors that are included and excluded in this study are given below:

\section{Included are}

A. Bangladesh Labor Act, 2006

B. Analyzing standard OHS Policy

C. Different policy of the factories etc.

\section{Excluded are}

1) Political intervention

2) Environmental effect

\section{Research methodology research design}

The study is aiming to examine the practice of health and safety issues in terms of BLA, 2006 on garments factories and the impact of these issues on factories efficiency. This research is based on descriptive methods. 


\section{Sources \& collection of data}

Qualitative, as well as quantitative data, used to analyze the existing condition of the health and safety compliance issues. In the study, primary data are used to answer the main research question. Questionnaire response, collected from the factories is used in the analysis. Apart from that, different published materials such as books, journals, magazines, and newspapers are also use as secondary data. We also use relevant information from different articles over the internet to obtain information about the garments industry of Bangladesh. To ensure the relevance, reliability and timeliness of secondary data are critically chosen depending on different criteria i.e. Analysis possibility, the expenditure level over the sources, quality of the data as well as the time spent in getting the data (Appendices).

\section{Sampling technique, sample size and data analysis}

A total of 200 respondents was interviewed from 7 garment factories with a convenience sampling method where every responded response appropriately. Due to the confidentiality, we cannot mention the name of the factories, though it is mentioned in the filled questionnaire (Factory A- 30 respondents, Factory B- 34 respondents, Factory C- 24 respondents, Factory D- 36 respondents, Factory E-30 respondents, Factory F-34 respondent, Factory G-12 respondents). The collected data will be analyzed based on different perspectives such as the workers, the perspective of the general people \& managers' perspective. Statistical tools, i.e. Microsoft Excel 2013 are used to analyze the data.

\section{Survey instrument}

Some information cannot be found elsewhere, such as books, newspapers, and electronic media. Questionnaires will allow us to gather this type of information. So, that is why the questionnaire survey is the most powerful method for this study to glean the data, and it is the research tool used in this particular study. Close-ended questions with one open-ended question included in the format. Respondents had the independent choice to put their feelings towards a particular statement. The scales have qualities, for example, Strongly Satisfied or Satisfied, Neutral, Strongly Dissatisfied, and Dissatisfied. The survey is a 5 Point Liker Scale that comprises of 32 inquiries. The scales that have been used are given below:

\begin{tabular}{lllll}
\hline $\begin{array}{l}\text { Strongly } \\
\text { dissatisfied }\end{array}$ & Dissatisfied & Neutral & Satisfied & $\begin{array}{l}\text { Strongly } \\
\text { satisfied }\end{array}$ \\
\hline I & 2 & 3 & 4 & 5 \\
\hline
\end{tabular}

\section{Limitations}

This study has some limitations. In this case, researching the collection of information was the main obstacle. And confidential information was the reason behind this. For the safeguard of their organizational policy, all information related to the study could not be supported by the administration. On the other hand, the Superintendence forces employees to grant answers in their support, during the period of the survey. In the next point, the size of the sample was not presentable for the proposed scenario. And the restriction of time led to having confined results as well. In the end, another limitation of employees for this study is the knowledge constraint. Because of the language barrier, some of the respondents keep themselves silent. They have faced difficulty with understanding research words.

\section{The following items describe statements about current health and safety hazards for the RMG workers}

\section{Health and hygiene}

The workplace is clean or not?

The ventilation system for workplace is standard or not?

Did they take effective measures to prevent accumulation of dust and fumes in work-room?

Did they take Effective measures to of disposal of wastes and effluents?

The water used in artificial humidification is pure or not?

The space for every worker at the workplace is sufficient?

Is there sufficient lighting system in every part of the establishment where workers are working or passing?

Is there pure drinking water available?

Is there sufficient number and hygienic latrine and urinal available for male and female workers?

Dust bean and Spittoon available for use?

\section{Safety}

Is there any inspection going about the safety of building and machinery and the specifying measures taken to prevent injury?

Precaution in case of fire with fire fighting apparatus and alternative connection stairway with each floor for escaping provided?

Every dangerous part of any machinery securely fenced by the safeguards of substantial construction?

Maintenance of dangerous machinery is carried by specially trained adult male worker or not?

Suitable devices for cutting off power in emergencies are maintained in every work-room or not?

Is there any automatic machine operates where workers are always passing?

Is every hoist and lift is made of sound material as well as properly maintained?

All floors, stairs, passages and gangways are of sound construction and properly maintained?

Excessive weights are carried or moved by any worker?

Suitable goggles are provided for the protection of workers where there is risk of injury to eyes?

\section{Other issues of health, hygiene and safety}

Is there any operation that causes serious risk of bodily injury, poisoning or disease to workers?

Any notice given on the occurrence of accidents, dangerous occurrences or certain disease?

Are female workers allowed to clean, lubricate of adjust any part of dangerous machinery?

\section{Welfare}

Is there sufficient supply of first-aid appliances?

Safety record book properly maintained or not?

Adequate and suitable facilities for washing and bathing are provided or not? 
Adequate number of canteens for the use of the workers is provided? Adequate and suitable shelters or rest rooms, and a suitable lunch room provided or not?

Suitable room for the use of children is maintained?

\section{OHS management system \& training}

Do they have any own OHS policy?

Do they maintain the guideline about OHS?

Is there any training session regarding OHS?

\section{Analysis \& findings}

\section{Conceptual framework (Figure I)}

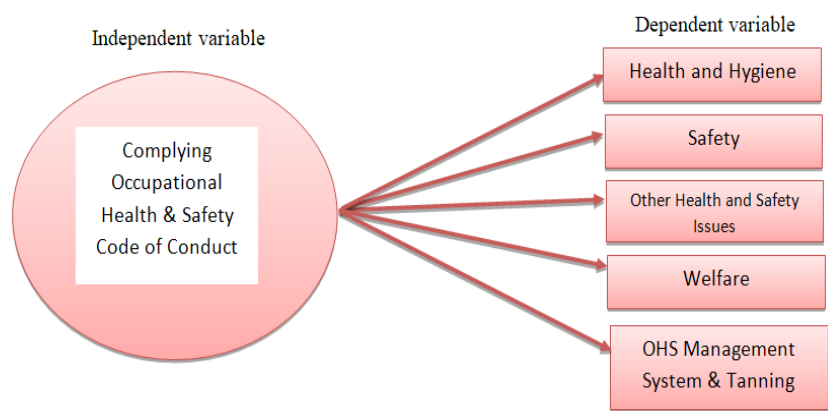

Figure I Conceptual framework.

\section{Quantitative data analyzing}

Gender of the respondents: $83 \%$ of Female and 17\% of Male of the total participants are participated in this survey. The percentage of respondents is shown in the pie chart (Figure 2).

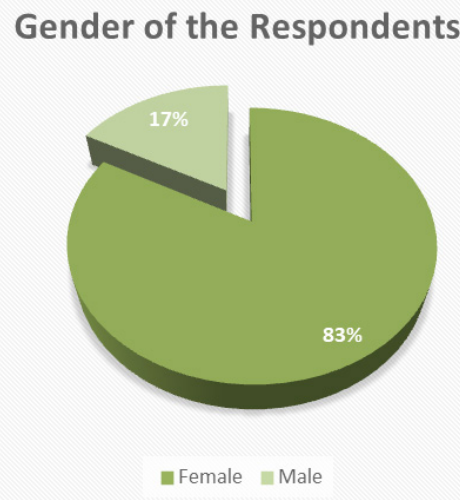

Figure 2 Gender of the respondents in pie chart.

Health and hygiene: Strongly Dissatisfied $=20$ (1\%), Dissatisfied $=100$ $(5 \%), \quad$ Neutral $=400 \quad(20 \%), \quad$ Satisfied $=1300 \quad(65 \%), \quad$ strongly Satisfied $=180(9 \%)$. This is graphically shown in Bar Diagram of Health and Hygiene.

From this above graph, we can say that $65 \%$ respondents are satisfied with health and hygiene issues and 20\% respondents are thinking that it is difficult to perceive clearly (Figure 3).

Safety: Strongly Dissatisfied $=40 \quad(2 \%)$, Dissatisfied $=120 \quad(6 \%)$, Neutral=300 (15\%), Satisfied=1380 (69\%), Strongly Satisfied=160 $(8 \%)$. This is graphically shown in Bar Diagram of Safety.
Opinion of Respondents on Health and Hygiene (in percentage)

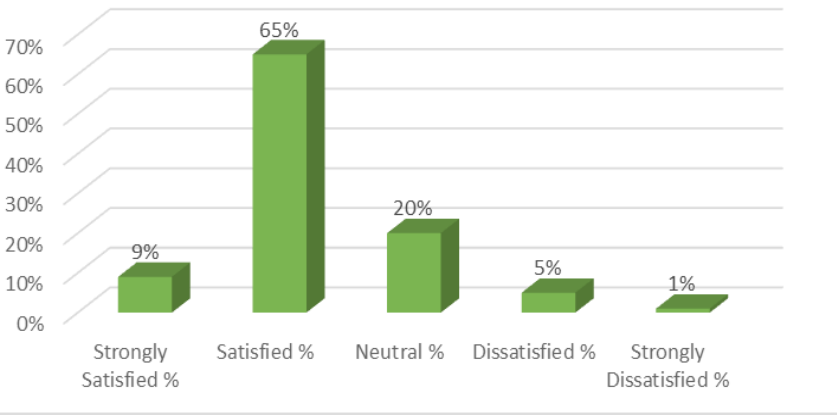

Figure 3 Opinion of respondents on health and hygiene in bar diagram.

From this above graph, we can say that $69 \%$ respondents are satisfied with safety issues and $15 \%$ respondents are thinking that it is difficult to perceive clearly (Figure 4).

\section{Opinion of Respondents on Safety (in percentage)}

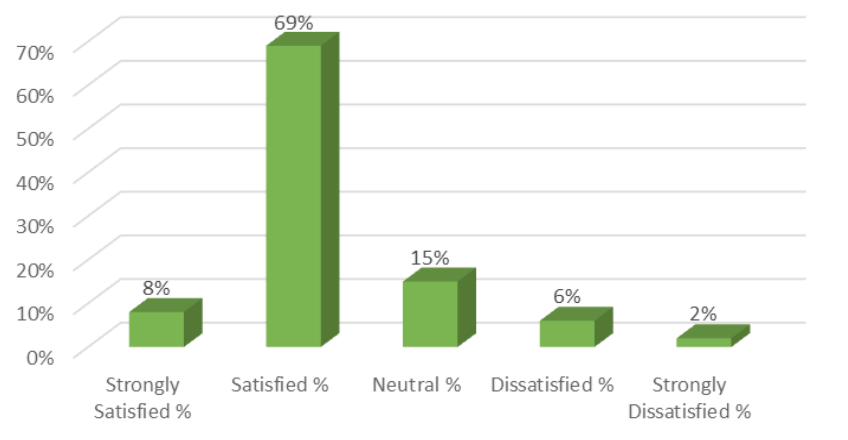

Figure 4 Opinion of respondents on safety in bar diagram.

Other issues of health, hygiene and safety: Strongly Dissatisfied $=12$ $(2 \%)$, Dissatisfied $=54(9 \%)$, Neutral $=126 \quad(21 \%)$, Satisfied $=360$ $(60 \%)$, strongly Satisfied $=48(8 \%)$. This is graphically shown in Bar Diagram of Other Issues of Health, Hygiene and Safety.

From this above graph, we can say that $60 \%$ respondents are satisfied with other issues of health, hygiene and safety issues and $21 \%$ respondents are thinking that it is difficult to perceive clearly (Figure 5).

Welfare: Strongly Dissatisfied=12 (1\%), Dissatisfied=96 (8\%), Neutral=228 (19\%), Satisfied=744 (62\%), Strongly Satisfied $=120$ $(10 \%)$. This is graphically shown in Bar Diagram of Welfare.

From this above graph, we can say that $62 \%$ respondents are satisfied with welfare issues and $19 \%$ respondents are thinking that it is difficult to perceive clearly (Figure 6).

OHS management system \& training: Strongly Dissatisfied $=0$ $(0 \%)$, Dissatisfied $=60 \quad(10 \%)$, Neutral=102 (17\%), Satisfied $=396$ $(66 \%)$, strongly Satisfied $=42(7 \%)$. This is graphically shown in Bar Diagram of OHS Management System \& Training.

From this above graph, we can say that $66 \%$ respondents are satisfied with OHS management system \& training issues and $17 \%$ respondents are thinking that it is difficult to perceive clearly (Figure 7). 


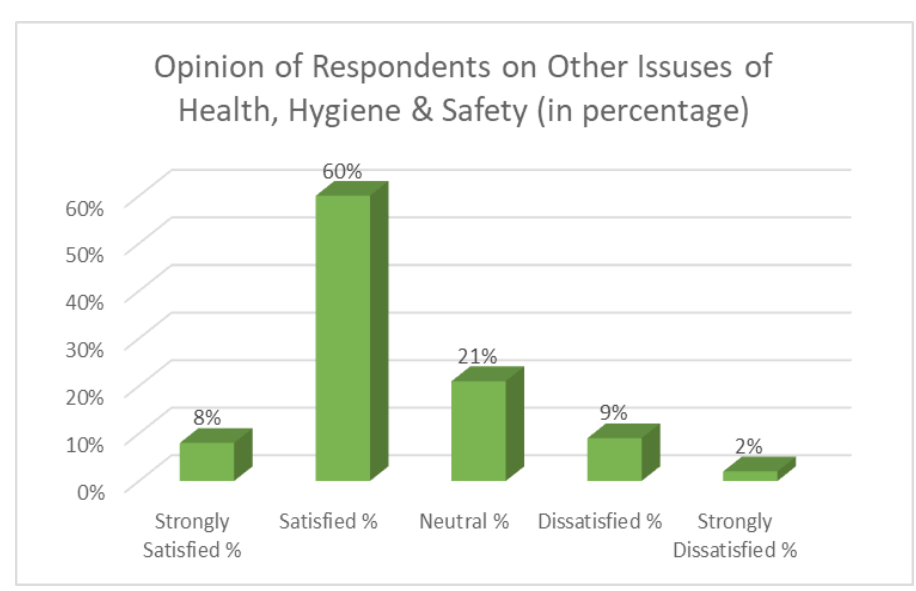

Figure $\mathbf{5}$ Opinion of respondents on other issues of health, hygiene and safety in bar diagram.

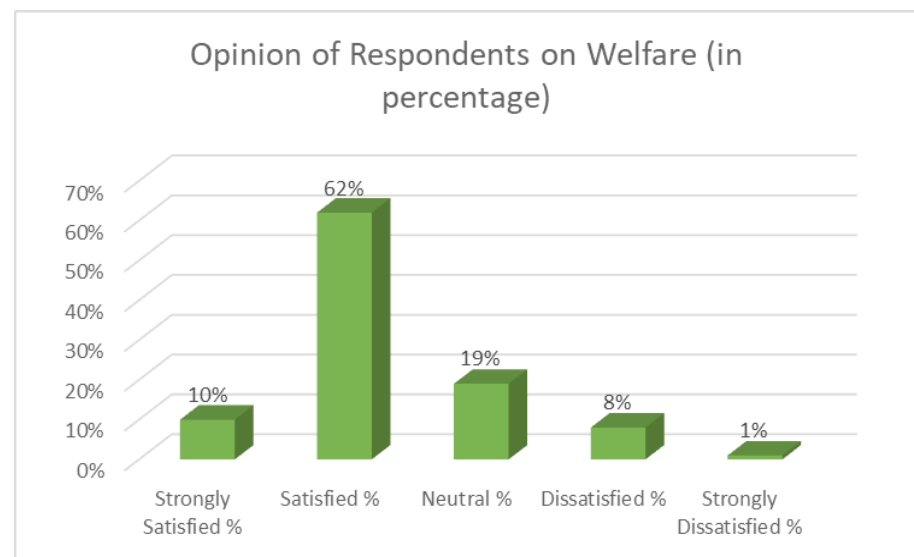

Figure 6 Opinion of respondents on welfare in bar diagram.

\section{Opinion of Respondents on OHS Management} System \& Training (in percentage)

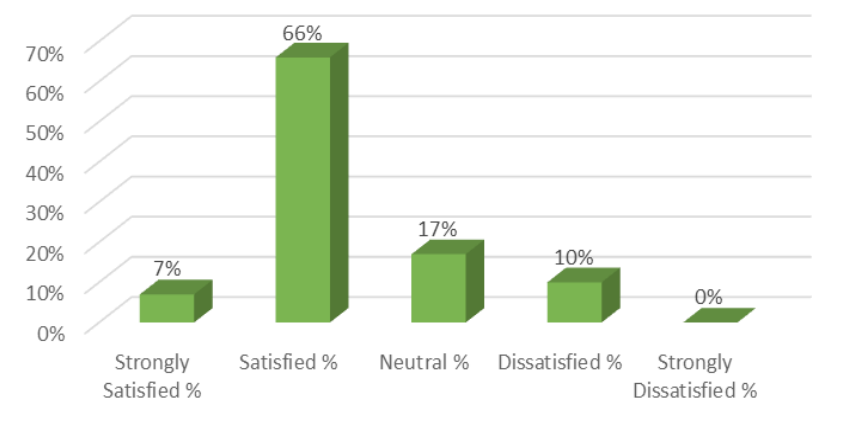

Figure 7 Opinion of respondents on OHS management system \& training in bar diagram.

\section{Discussion \& recommendation}

The prime point of discussion in this report is the security of workers in one of the most hazardous industry in Bangladesh, RMG industry. The harsh reality of insufficient wage, hazardous work condition, unstable job security etc. faced by the illiterate workers of Bangladesh needs amendment. Although laws are presenting an effort to protect workers, the application of these laws is rare according to various newspaper conducted research (Hossain, 2006). The Bangladesh Labor Code, 2006 is latest law passed by the parliament regarding labor code and henceforth it has been used as the basis for analysis and research in this thesis paper. ${ }^{6-20}$

We aimed our best in this research to study the health and safety hazards of garments workers predicated on the participation of workers and managers. We found that most of the factories are maintaining the standard health and safety programs in terms of the BLA, 2006, though many of the factories did not comply with all issues and guidance mentioned in the BLA, 2006. We found that that $65 \%$ respondents are satisfied with health and hygiene issues and $20 \%$ respondents are neutral, $69 \%$ respondents are satisfied with safety issues and $15 \%$ respondents are neutral, $60 \%$ respondents are satisfied with other issues of health, hygiene and safety issues and $21 \%$ respondents are neutral, $62 \%$ respondents are satisfied with welfare issues and $19 \%$ respondents are neutral, $66 \%$ respondents are satisfied with OHS management system \& training issues and $17 \%$ respondents are neutral. We withal found on our survey that many workers do not have the least erudition about occupational health and safety standards to maintain in RMG industries. Moreover, though some of the workers seemed to be concerned about the hazardous working position and inequitable welfare provision, they did not optate to reveal the genuine situation while doing surveys due to the trepidation of missing jobs or being bothered by the authority later. So, we cannot verbalize that this result is $100 \%$ precise and exhibiting the authentic picture of our RMG industry. In our survey, we examine the recent development in the Bangladesh garment industry in terms of worker's health and safety, rights. The paper finds that the garment industry has done paramount ameliorations in all categories in recent times. Paramount efforts have been taken to ascertain worker's safety at work, the situation of workers' rights has withal amended. However, some shortcomings are additionally traced in our survey that requires to be addressed felicitously ${ }^{21-32}$ :

i. Most of the factories (90\%) does not comply all the rules and regulation mentioned in the BLA, 2006. This need to be taken care of.

ii. The internal healthcare system should be encouraging, as well as safety committees need to be effective.

iii. Most of the respondent (54\%) said they did not receive proper training on occupational health and safety issues. The authorities should take more action about this matter.

iv. Most of the factories do not have $(65 \%)$ a canteen as mentioned in the law though they maintained suitable lunch room. However, they should provide canteen facalities.

v. Most of the factories does not run (54\%) training program regarding OHS. The authorities should take more action about this matter.

vi. All the garments building should maintain the building code likeexit, lift, generator, and Fire safety practice compliance require bettering in the industries.

vii. Compensation and agreement should be strictly maintained by the authority.

viii. Those workers who become disabling should restore by alternative jobs or any other source of income. 
ix. The long-term target-oriented program should be adopted to perpetuate the current development. ${ }^{33-38}$

\section{Conclusion}

A risk-free and healthy workplace domain is a foundational right of all workers (UDHR, 1948). Workers' rights are defended by both international human rights instruments as well as domestic laws. However, due to the lack of safeguard apparatus, enforcement of labor laws, and indisposition of some people, these predicaments remain unresolved. Garment manufacturers continuing to construct garment factories without suitable substructure and amenities are unjustifiable. Since it is a vast and one of the major industries of Bangladesh, a large sum of workers can be employed in this sector which can diminish the unemployment level and the deficit level as well. The liability of the owner should be deduced after mishaps or injuries and violations of laws. Otherwise, we will have controversies shortly about these types of comprehensive dereliction of human rights and may lose our peregrine buyers. Simultaneously, appropriate enforcement of general and international standards should be made compulsory to halt and reduce the construction of death traps for workers. Foundationally, a holistic approach should be organized not only for the construction of RMG factories but also for the area encompassing them, to avert the ultimate loss of life. It may not be possible to adapt the prevailing extemporary framework instantly but the gradual enhancement is possible in the long term by proper planning and design.

\section{Acknowledgments}

None.

\section{Funding}

None.

\section{Conflicts of interest}

The authors have no conflicts of interest regarding the publication of this paper.

\section{References}

1. Bangladesh garments manufacturers \& exporters association. 2019.

2. Anu M. Wealth and deprivation: ready-made garments industry in Bangladesh. Economic and Political Weekly. 2011;45(34):23-27.

3. Morshadul H, Appel M. Risks management of ready-made garments industry in Bangladesh. International Research Journal of Business Studies. 2017:1-13.

4. David LG. Occupational safety and health. Boston: Pearson Education; 2019.

5. Alexander C. WITHDRAWN: reprint of "factors in successful occupational safety programs. Journal of Safety Research. 2013.

6. Apu A Abrar. Compliance in textile \& clothing sector in Bangladesh: difficulties in understanding and implementation. Bangladesh Textile Today; 2012.

7. Apparel working conditions still poor. The Daily Star; 2015.

8. Alamgir F, Cairns G. Economic inequality of the badli workers of Bangladesh: Contested entitlements and a 'perpetually temporary'lifeworld. Human Relations. 2015;68(7):1131-1153.

9. Accord. Quarterly Aggregate Report. 2016.
10. Alliance. Alliance for Bangladesh worker safety third annual report. 2016.

11. Department of inspection for factories and establishments. 2015.

12. ILO. Union registrations rise sharply in Bangladesh garment sector: New labor laws pave way to improve conditions, workers' rights. 2014.

13. ILO. Improving working conditions in the ready- made garment industry: Progress and achievements. (2016).

14. Khan ZR, Rodrigues G. Human before the garment: Bangladesh tragedy revisited. ethical manufacturing or lack thereof in garment manufacturing industry. World. 2015;5(1).

15. Sen A. Equality of what? In: McMurrin S, editor. Tanner lectures on human values. Salt Lake City, UT: University of Utah Press and Cambridge: Cambridge University Press; 1980.

16. Sharif PA, Islam ME, Kabir RA. A study on occupational health \& safety practices in RMG factories of Bangladesh in accordance with compliance after Rana plaza incident. The International Journal of Business \& Management. 2015;3(5):214.

17. Shoron AA. Workers' safety in Bangladeshi readymade garments industry. 2015.

18. Uddin M. How Bangladeshi readymade garments industry can be competitive in the global market. 2014

19. Ali YM, Sarwar JM, Sarker MC, et al. Core decompression by laser osteoperforation: a preliminary report of new and minimally invasive modality for the treatment of avascular necrosis of the femoral head. Malaysian Journal of Medical and Biological Research. 2014;1:9-17.

20. Bangladesh apparel factory collapse: background, in brief; mary jane bolle, specialist in international trade and finance. 2013.

21. Bangladesh Garment Manufacturers and Exporters Association (BGMEA). Industry Strengths.

22. Bangladesh Knitwear Manufacturers and Exporters Association (BKMEA). Export performance of RMG of Bangladesh for 2012-13, 2013-14 \& 2014-15 (Facts and Figures).

23. Bernicat Marcia. US partnering with Bangladesh to help avoid another Rana Plaza like tragedy. The Independent; 2015. 7 p.

24. Bernicat, Marcia. Rana Plaza, two-year anniversary. The Daily Star; 2015.7 p.

25. Bhuiyan, Kauser. Bangladesh garment factory disaster timeline. stein and partners (Bangladesh). 2013

26. Coppée Georges H. Occupational health services and practice. ILO encyclopedia of occupational health and safety. 2011.

27. Ministry of labour and employment, government of the people's republic of Bangladesh. Activities Related to RMG Sector.

28. Ministry of labour and employment, government of the people's republic of Bangladesh. Steps taken by Government and other related stakeholders after Rana plaza collapse at savar on 24th April 2013. 2015.

29. Not even a single factory safe yet. The Daily Star; 2015.

30. RMG Industry. Social code of conduct fact sheet.

31. Promotion of Social and Environmental Standards in the Industry (PSES). Occupational Health and Safe (OHS) in the RMG Sector. Occupational Health and Safety (OHS) fact sheet.

32. Rahman Md. Arifur, Hossain Mir Sohrab. Compliance practices in garments industries of Bangladesh. Journal of Business and Technology (Dhaka). 2010;5(2):72-75. 
33. Laws of Bangladesh.

34. http://www.bgmea.com.bd/home/pages_test/TradeInformation

35. http://www.nla.gov.au/openpublish/index.php/lmd/article/ viewFile/2269/3148
36. http://www.opendemocracy.net/debates/article- 6-30-1840

37. http://www.worldbank.org/gender/prr

38. http://journals.abc.us.org/index.php/ajtp/article/view/Feleke 